\title{
MATHEMATICAL MODELLING OF A HYBRID MICRO-COGENERATION GROUP BASED ON A FOUR STROKE DIESEL ENGINE
}

\author{
VALENTIN APOSTOL, University Politehnica of Bucharest, Faculty of Mechanical and Mechatronics \\ Engineering, e-mail: apostol@marco-alex.ro \\ TUDOR PRISECARU, University Politehnica of Bucharest, Faculty of Mechanical and Mechatronics Engineering, \\ e-mail: tudor_prisecaru@mail.com
}

CRISTIAN PETCU, Rokura Company, e-mail: cristian.petcu@rokura.ro

ALEXANDRU DOBROVICESCU, University Politehnica of Bucharest, Faculty of Mechanical and Mechatronics Engineering, e-mail: adobrovicescu@yahoo.com

MĂLINA PRISECARU, University Politehnica of Bucharest, Faculty of Mechanical and Mechatronics Engineering, e-mail: malina prisecaru@yahoo.com

GHEORGHE POPESCU, University Politehnica of Bucharest, Faculty of Mechanical and Mechatronics Engineering, e-mail: popescu8m@yahoo.com

HORAȚIU POP, University Politehnica of Bucharest, Faculty of Mechanical and Mechatronics Engineering, e-mail: pophoratiu2001@yahoo.com

CRISTINA CIOBANU, University Politehnica of Bucharest, Faculty of Mechanical and Mechatronics Engineering, e-mail: ciobanu_cristina_26@yahoo.com

ELENA POP, University Politehnica of Bucharest, Faculty of Mechanical and Mechatronics Engineering, e-mail: alina_ela@yahoo.com

ADRIAN UNTEA, PhD Student, University Politehnica of Bucharest, Faculty of Mechanical and Mechatronics Engineering, e-mail:

MAHDI HATF KADHUM, PhD Student, University Politehnica of Bucharest, Faculty of Mechanical and Mechatronics Engineering, e-mail: hatfmahdi@yahoo.com

VIOREL BĂDESCU, University Politehnica of Bucharest, Faculty of Mechanical and Mechatronics Engineering, e-mail: badescu@theta.termo.pub.ro

\begin{abstract}
The paper presents a part of the work conducted in the first stage of a Research Grant called "Hybrid micro-cogeneration group of high efficiency equipped with an electronically assisted ORC" acronym GRUCOHYB. The hybrid micro-cogeneration group is equipped with a four stroke Diesel engine having a maximum power of $40 \mathrm{~kW}$. A mathematical model of the internal combustion engine is presented. The mathematical model is developed based on the Laws of Thermodynamics and takes into account the real, irreversible processes. Based on the mathematical model a computation program was developed. The results obtained were compared with those provided by the Diesel engine manufacturer. Results show a very high correlation between the manufacturer's data and the simulation results for an engine running at $100 \%$ load. Future developments could involve using an exergetic analysis to show the ability of the ORC to generate electricity from recovered heat.
\end{abstract}

Keywords: irreversible processes, simulation, variable operation parameters, result validation

\section{Introduction}

The paper presents a part of the work conducted in the first stage of a Research Grant called "Hybrid micro-cogeneration group of high efficiency equipped with an electronically assisted ORC" acronym GRUCOHYB. The electricity and heat micro-generation system is equipped with a four-stroke Diesel engine with a maximum power of $40 \mathrm{~kW}$. The design entails the recovery of the heat exhausted by the engine through its cooling system and of that from the exhaust gas. The recovered heat is intended to be used in order to obtain electricity through a Rankine cycle-based system using an organic substance as its working fluid (ORC), as well as to heat a thermal agent. 
The main elements of the micro-generation system consist of: the internal combustion engine, thermal coupling through the engine-to-ORC system heat exchangers; the ORC system. The overall mathematical model of each subsystem of the micro-generation and global systems, enables a simulation of the working system based on the variation of its functional and design parameters, which will result in the output of the optimum solution.

\section{Mathematical model of the internal combustion engine}

The engine type is overcharged Diesel. The mathematical model, based on the laws of thermodynamics [1-4], takes into account the real, irreversible processes that accompany the intake scavenging phenomenon, the free exhaust of flue gas, pressure losses at the engine cylinder intake and exhaust as well as at the turbocharger and compressor. The mathematical model takes into account the combustion process and the change in composition of the working agent as it traverses the engine work cycle.

The computation cycle of a turbocharged compression-ignited engine is illustrated in Fig. 1.

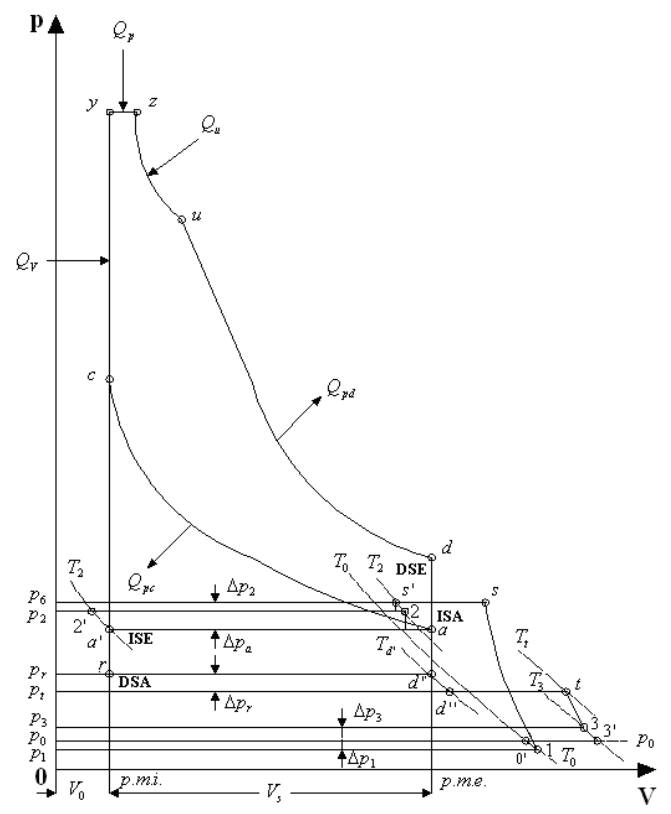

Fig. 1- Computation cycle of a turbocharged compression-ignited engine

\subsection{Study of gas exchange processes}

The blueprint of the gas exchange processes is illustrated in Fig. 2. Phase 2. $\alpha$ corresponds to the moment the exhaust valve opens and phase 2. $\beta$ to the end of the forced exhaust when the $\mathrm{m}_{\mathrm{r}}$ residual gas amount is left in the cylinder. The gas in the intake gallery carries out the cylinder run effect and finally its filling.

By integrating the differential equation for the first law of thermodynamics between states $\alpha$ and $\beta$ we obtain the $T_{e}$ exhaust gas temperature calculation equation.

$$
\frac{T_{e}}{T_{d}}=\frac{1}{n_{e}} \cdot \frac{1+\left(\frac{\varepsilon-1}{\varepsilon} n_{e}-1\right) \frac{p_{r}}{p_{d}}}{1-\frac{\rho_{r}}{\varepsilon}\left(\frac{p_{r}}{p_{d}}\right)^{1 / k_{e}}}
$$

Where $n_{e}$ is exhaust process adiabatic coefficient. 
The study of the run and intake processes takes place by integrating the energy ratio differential equation between the moment the exhaust valve opens (DSA) (phase $\beta$ ) and the time it closes (ISA) (phase $\gamma$ ).
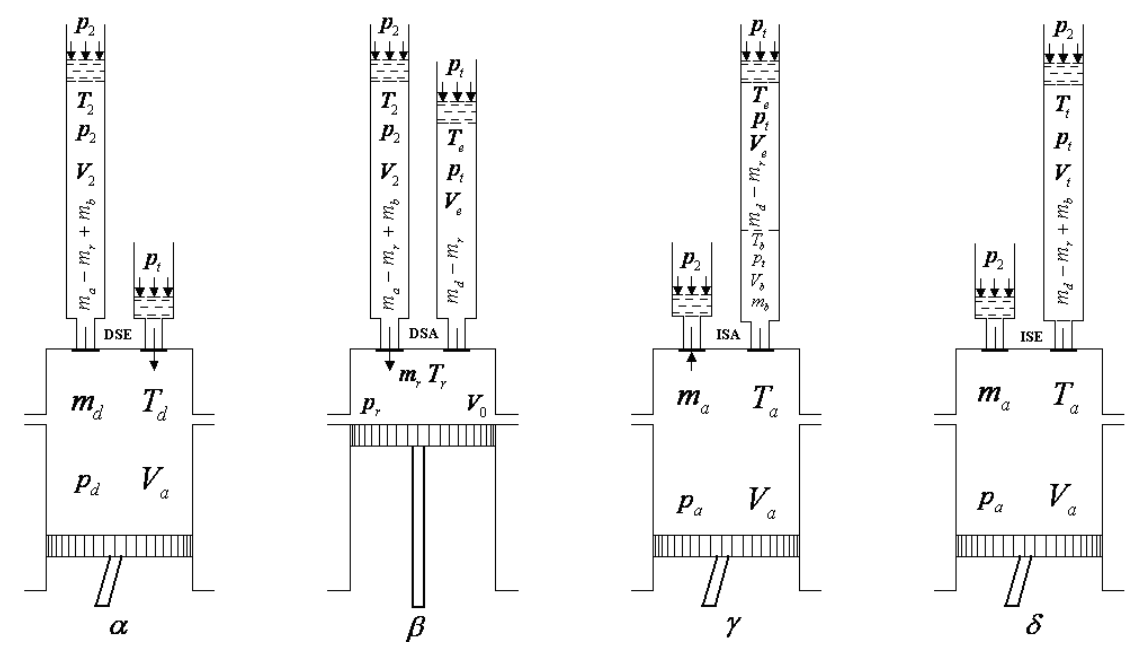

Fig. 2- Blueprint of the gas exchange processes

The work exchanged by the cylinder-pipe system and the exterior during the run and intake processes is expressed by the relation:

$$
L_{\beta-\wp}=p_{a} \cdot V_{a}\left\{\frac{\varepsilon-1}{\varepsilon}+\left(1-\frac{T_{a}}{T_{r}} \cdot \frac{p_{r}}{p_{a}} \cdot \frac{1}{\varepsilon}\right)\left[(\beta-1) \frac{T_{b}}{T_{a}}-\beta \frac{T_{2}}{T_{a}}\right]\right\}
$$

The $\mathrm{T}_{\mathrm{b}}$ temperature of the mixture of air and flue gas that took part in the run process and were exhausted from the cylinder becomes:

$$
\frac{T_{b}}{T_{a}}=\frac{n_{a}\left[\beta\left(1-g_{r}\right) \frac{T_{2}}{T_{a}}-1\right]+\frac{1}{\varepsilon}\left(n_{a}+\frac{k_{a}-1}{k_{e}-1} \cdot \frac{p_{r}}{p_{a}}-1\right)}{n_{a}(\beta-1)\left(1-g_{r}\right)}
$$

\subsubsection{Determining gas temperature at the turbine intake}

This temperature is the result of an isobar mixing of gases having the temperatures $\mathrm{Te}$ and $\mathrm{Tb}$

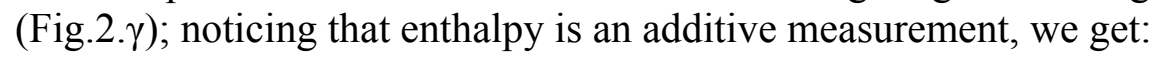

$$
H_{t}=H_{b}+H_{e}
$$

and continuing (Fig.2.8):

$$
\left(m_{d}-m_{r}+m_{b}\right) c_{p_{g}} T_{t}=m_{b} c_{p_{a}} T_{b}+\left(m_{d}-m_{r}\right) c_{p_{g}} T_{e}
$$

The energy balance ration (5) enables the calculation of temperature $T_{t}$ upstream of the turbine based on the run coefficient $\beta$ :

$$
T_{t}=\frac{\beta-1}{\beta+d} \cdot \frac{k_{a}}{k_{e}} \cdot \frac{k_{e}-1}{k_{a}-1} T_{b}+\frac{1+d}{\beta+d} T_{e}
$$

\subsubsection{Determining gas temperature at the turbine intake}

Taking into account the adiabatic efficiency of the turbine, the equation of the $\mathrm{T}_{3}$ gas temperature at the turbine exhaust becomes:

$$
T_{3}=\left\{1-\eta_{T}\left[1-\left(\frac{p_{3}}{p_{t}}\right)^{\frac{k_{T}-1}{k_{T}}}\right]\right\} T_{t}
$$




\subsection{Study of the burn process}

The burn efficiency enables the correlation of the heat released by burning the fuel to the engine design parameters.

$$
\eta_{a r}=\frac{Q_{g}}{Q_{c b_{i n}}}=\frac{Q_{c b}-\left|Q_{p_{a r}}\right|}{Q_{c b}}=1-\frac{\left|Q_{p_{a r}}\right|}{Q_{c b}}
$$

Where $Q_{c b}$ is the heat created by burning the fuel, $Q_{g}$ the heat received by the flue gas and $Q_{p_{a r}}$ is the heat lost through the burn chamber walls.

The heat developed by burning the fuel is calculated like this:

$$
Q_{c b}=m_{c b} \cdot H_{i}
$$

Where $m_{c b}$ is the amount of fuel burned in the cylinder during each cycle and $\mathrm{H}_{\mathrm{i}}$ is the lower calorific power of the fuel.

The amount of fuel consumed during a cycle is calculated by the formula:

$$
m_{c b}=\frac{m_{a e r}}{\alpha \cdot L_{0}}=\frac{m_{a e r}}{m_{a d}} \cdot \frac{m_{a d}}{\alpha \cdot L_{0}}
$$

where $\mathrm{L}_{0}$ is the minimum air required to burn one $\mathrm{kg}$ of fuel and $\alpha$ the minimum burn air coefficient. The thermal load of the engine displacement unit:

$$
q_{c b}=\frac{Q_{c b}}{V_{s}}=d \cdot \eta_{v} \cdot \rho_{0} \cdot H_{i}\left[\frac{J}{m^{3}}\right]
$$

Forcefully filling the cylinder by overcharging acts on its volumetric thermal load, which increases the higher the overcharge pressure $p_{s}$ is, and the cooling degree $\tau_{R}$ of the air in the cooler is higher.

\section{Simulating engine behavior based on variations of operating parameters}

Based on the mathematical model presented before, a computation program has been developed and solved using the EES [5] software. The program simulates the engine behavior that is based on variations of the operating parameters.

The simulation aim was to gather information pertaining $\dot{m}_{c b}$ fuel consumption, the temperature of the flue gas exhausted from the engine $T_{3}$ (at the turbine exhaust) and the engine $\eta_{\mathrm{em}}$ efficiency when modifying the $\alpha$ air excess coefficient, the overcharge pressure $p_{s}$ and the maximum pressure $p_{z}$ of the operating cycle. The functional and design characteristics of the four-stroke overcharged Yanmar [6] Diesel engine are listed in Table 1.

Table 1

Functional and design characteristics of the Diesel engine

\begin{tabular}{|c|c|c|}
\hline Characteristic & Measurement Unit & Value \\
\hline Power & $\mathrm{kW}$ & 37,7 \\
\hline Rotation speed & $\mathrm{rot} / \mathrm{min}$ & 1500 \\
\hline Cylinder diameter, D & $\mathrm{mm}$ & 98 \\
\hline Piston stroke, $\mathrm{S}$ & $\mathrm{mm}$ & 110 \\
\hline Capacity, $V_{S}$ & $\mathrm{dm}^{3}$ & 3,319 \\
\hline Compression ratio, $\varepsilon$ & - & 18,1 \\
\hline
\end{tabular}

The influence of the change of the air excess coefficient on the engine performances is illustrated in Fig. 3 to Fig. 5. 


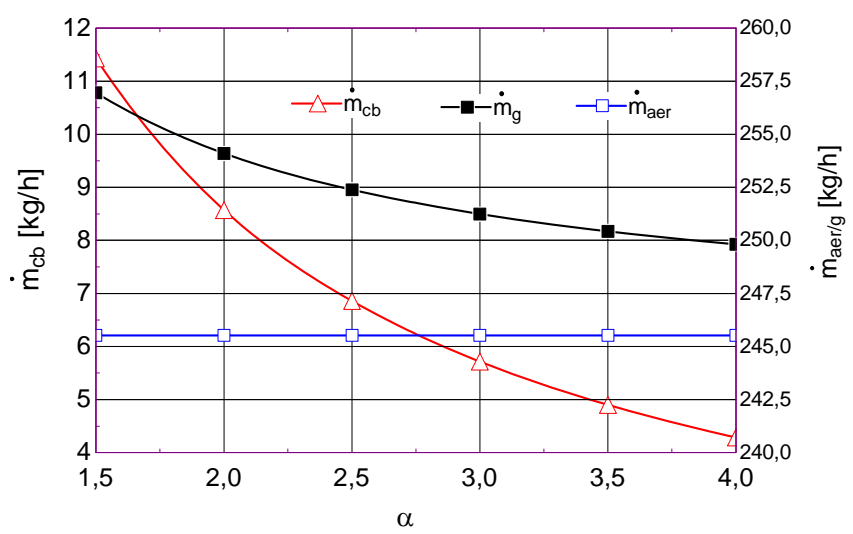

Fig.3 - The influence of the air excess coefficient $\alpha$ on hourly fuel, air and exhaust gas flows $\left(\mathrm{p}_{\mathrm{s}}=1,5\right.$ bar, $\left.\mathrm{t}_{0}=25^{\circ} \mathrm{C}\right)$

As it was to be expected, increasing the air excess coefficient leads to a rapid decrease in fuel consumption, with a corresponding reduction in engine load. In the illustration in figure 3 , the engine intake air flow is not affected by the change in the air excess coefficient. This is probably due to the fact that the mathematic model, on which the engine running is simulated, holds that the other determining functional engine parameters are unchanged. The experimental study will provide precious information on how the engine behaves when the decision parameters vary, which will serve in correlating and improving the mathematical model.

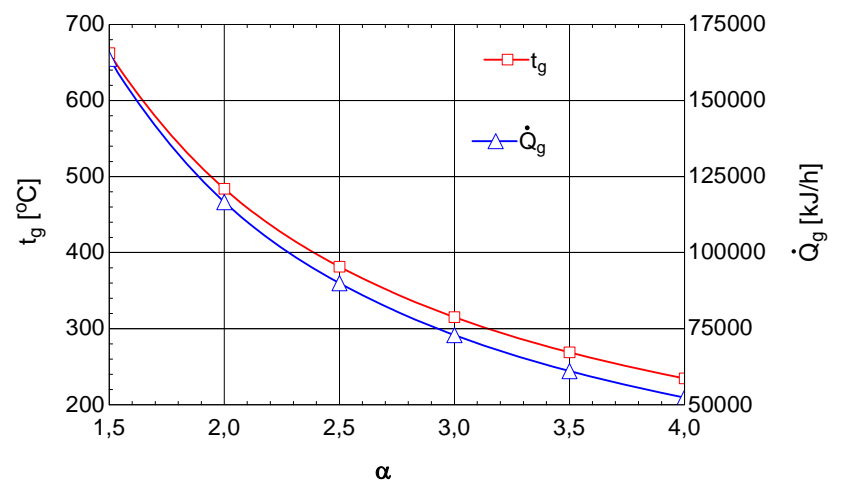

Fig.4 - Influence of the air excess coefficient $\alpha$ on the exhaust gas temperature and the heat available in the exhaust gas $\left(\mathrm{p}_{\mathrm{s}}=1,5 \mathrm{bar}, \mathrm{t}_{0}=25^{\circ} \mathrm{C}\right)$

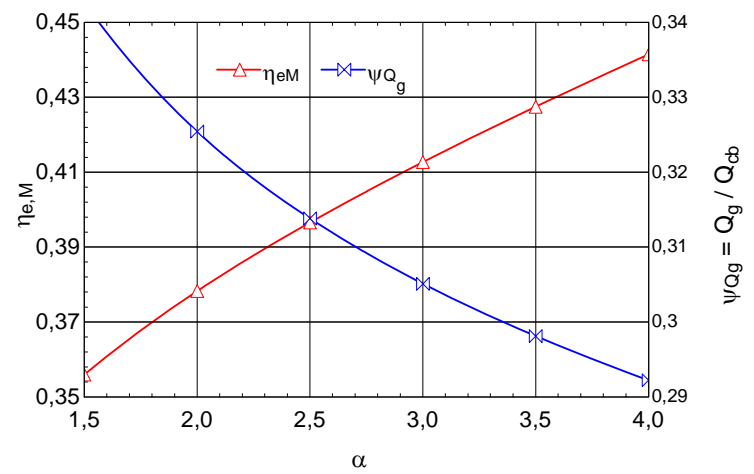

Fig.5 - Influence of the air excess coefficient $\alpha$ on the $\eta_{\mathrm{eM}}$ engine efficiency and on the $\psi_{\text {Qg }}$ percentage of available heat in the exhaust gas from the heat generated by burning the fuel

Increasing the air excess coefficient $\alpha$ leads to a rapid decrease of the exhaust gas temperature, a decrease which reduces, at the same pace, the amount of recoverable heat from the exhaust gas.

Figure 5 presents the influence of the excess air coefficient $\alpha$ on the $\eta_{M}$ engine efficiency and on the $\psi_{\text {Qg }}$ percentage of available heat in the exhaust gas from the heat generated by fuel burning.

Decreasing the exhaust gas temperature and as a consequence the potential of recoverable heat from the exhaust gas leads to a decrease in the fraction of available heat in the exhaust gas 
compared to the heat introduced by fuel burning. A comparison of the results obtained by simulating the engine operation and those presented by the manufacturer are listed in Tables 2 .

Comparison between simulation results and manufacturer's data

\begin{tabular}{|c|l|c|l|l|l|l|l|}
\hline \multicolumn{2}{|c|}{$\alpha$} & \multicolumn{2}{c|}{$\dot{m}_{c b}[\mathrm{~kg} / \mathrm{h}]$} & \multicolumn{2}{c|}{$\dot{m}_{g}[\mathrm{~kg} / \mathrm{h}]$} & \multicolumn{2}{c|}{$\mathrm{t}_{\mathrm{g}}\left[{ }^{\circ} \mathrm{C}\right]$} \\
\hline Model & Design & Model & Design & Model & Design & Model & Design \\
\hline 2 & 2.06 & 8.573 & 8.5075 & 254.1 & 259.55 & 483.9 & 480 \\
\hline \multicolumn{2}{|c|}{$\dot{Q}_{g}[\mathrm{~kJ} / \mathrm{h}]$} & \multicolumn{2}{|c|}{$\eta_{\mathrm{M}} \%$} & \multicolumn{2}{c|}{$\psi_{\mathrm{g}} \%$} & \multicolumn{2}{c|}{$\mathrm{t}_{\mathrm{s}}\left[{ }^{\circ} \mathrm{C}\right]$} \\
\hline Model & Design & Model & Design & Model & Design & Model & Design \\
\hline 116610 & 102369 & 37.83 & 37.98 & 32.54 & 28.64 & 369 & 366.29 \\
\hline
\end{tabular}

The comparative analysis shows a very high correlation between the experimental data and the simulation results for an engine running at $100 \%$ load. Instead of the energy potential for recovering heat from exhaust gas, which in no way reflects the ability to generate electricity using the ORC cycle, an exergetic analysis is recommended $[7,8]$

\section{Conclusions}

The paper presents a part of the results obtained in a first stage of a Research Grant called "Hybrid micro-cogeneration group of high efficiency equipped with an electronically assisted ORC" acronym GRUCOHYB. The micro-cogeneration group is equipped with a $40 \mathrm{~kW}$ overcharged Diesel engine. The aim of the research is to recover heat from the exhaust and cooling systems of the Diesel engine and convert it into electricity using an ORC based system. A mathematical model of the internal combustion engine is presented. The mathematical model is developed based on the Laws of Thermodynamics and takes into account the real, irreversible processes of scavenging during the intake, free evacuation of exhaust gasses, pressure losses during the engine cylinders intake and exhaust stages and pressure losses at the inlet and outlet of the turbocharger and compressor. Also the combustion process and the change in composition of the working agent as it traverses the engine work cycle were taken into account. Based on the mathematical model a computation program was developed and solved using the EES software, simulating the engine behavior based on variations of the operating parameters. The results obtained were compared with those provided by the Diesel engine manufacturer. Results show a very high correlation between the manufactures data and the simulation results for an engine running at $100 \%$ load. Future developments could involve using an exergetic analysis to show the ability of the ORC to generate electricity from the recovered heat.

\section{References}

[1] Radcenco, Vs., Grünwald, B., Danescu, A. (1971). A cycle model for the study of overcharged compressionignited engine performance optimization, Bul. Pol. Inst. Bucharest, Vol. XXXIII (4).

[2] Radcenco, Vs. (1976). The study of irreversible processes in piston detonators, Phd Thesis - Technical thermodynamics and thermal machines. Irreversible processes, EDP Bucharest.

[3] Apostol, V. (1996). The study of irreversible processes in piston detonators, PhD Thesis, University Politehnica of Bucharest.

[4] Moran M.J., Shapiro. (2010). Fundamentals of Engineering Thermodynamics, Willey.

[5] *** EES-Engineering Equation Solver, http://www.fchart.com/

[6] http://www.yanmarengines.co.uk

[7] Sayin, C., Hosoz, M., Canakci, M., Kilicaslan, I. (2006). Energy and exergy analyses of a gasoline engine, International Journal of Energy Research, (www.interscience.wiley.com) DOI:10.1002/er.1246.

[8] Dobrovicescu A. (2007). The principles of exergoeconomic analysis, Politehnica Press. 